\title{
Knowledge Exchange and Social Learning Opportunities in Direct Agri-Food Chains
}

\author{
Antonio P. Volpentesta, Salvatore Ammirato, and Marco Della Gala \\ Department of Electronics, Computer Science and Systems, University of Calabria \\ via P. Bucci, 42lC, 87036 Rende (CS), Italy \\ \{ammirato, mdellagala, volpentesta\} adeis.unical.it
}

\begin{abstract}
In direct agri-food chains (DAFCs), farmers and consumers are brought together with the aim of shortening, localizing and synergizing an agrifood chain. As food moves from the farm to the fork, all the economic activities are performed by farmers/producers or consumers, and none intermediary is required to handle an agri-food product before it is consumed. Any DAFC form provide a sort of liminal space for social learning and for local lay knowledge exchange, through face-to-face interactions. In this paper, we investigate the relationship between face-to-face interaction attributes and the learning opportunity domain of DAFCs that exhibit a same basic form. Our study is mainly based on qualitative data obtained from case studies reported in literature, field observations and informal interviews to various DAFC actors.
\end{abstract}

Keywords: agri-food, direct marketing, knowledge exchange, social learning.

\section{Introduction and Backgrounds}

Over recent years, agribusiness has been facing new challenges due to deregulation and globalization of markets. Mainstream agrifood systems are controlled by a small number of big organizations that monitor every transaction among millions of disconnected producers and consumers. This has led to the loss of decisional power for farmers/producers and to the 'crisis of trust' in 'placeless and faceless' massproduction for consumers [1], [2].

Agri-food SMEs are subjected to a continuous imbalance of their bargaining power; they suffer the cost-price squeeze and unfair contractual agreement, rising production costs and declining commodity prices thus reducing their profitability [1], [2]. The increasing disconnection between farming and food as well as producers and consumers, led to a widening consensus that radical changes are needed in agri-food systems. First efforts to overcome these limits are noticed since the ' 80 s, when farmers, and other people or organizations have started organizing themselves spontaneously in order to solve their problems and those of rural communities.

In more recent years, scholars are helping farmers to develop new and alternative business models characterized by a re-connection or close communication among producers and consumers, allowing the development of new forms of relationship and governance of the actors' network and also enhancing a re-distribution of value for 
primary producers.[3] In literature, the umbrella term alternative agrifood networks (AAFNs) is used to indicate all these forms of collaborative development. AAFNs are alternative to the organizational logic of dominant agri-food systems based on long and multinational supply chains. They aim to shorten the physical, social and economic distance between world production and world consumption [2].

As a more specific term of AAFNs, Direct Agri-Food Chains (DAFCs) refer to AAFNs where all economic activities are performed by only two types of actors (namely, producers and consumers). In a DAFC, there are no intermediaries, thus a lot of commitment from farmers and consumers is required, as they have to perform activities (e.g. packaging, transportation, marketing, customer relationship management) that are often conducted by other middle-men.

In a DAFC, an agri-food product is 'embedded' with value-laden information, concerning the mode of production, provenance and distinctive quality assets of the product, when it reaches the consumer. DAFCs are configurable as learning systems where interactions and knowledge exchange, between producers and consumers, enable learning opportunities (shortly, LOs) and let network members benefit from shorter distances, better information flow and greater trust. LOs lie in face-to-face interactions (F2FI) between consumers and producers which happen within the social, economic, physical and environmental context of a DAFC initiative.

In our exploratory study, we investigate the relationship between F2FI attributes and the LO domain of DAFCs that exhibit a same basic form. "Learning opportunities" is a consolidated field of research since sixties, but studies have been conducted in school or educational context, and mostly focalized on how LOs impact on student achievement. Although many scholars affirm that AAFNs provide LOs, none of them deal with the identification of F2FI attributes impacting on LOs.

The paper is organized as follows. In section 2, we characterize the DAFCs as learning systems. In section 3 a brief classification of DAFC basic forms is proposed. In section 4, we present the objects (i.e. the F2FI and the LO domain elements) of the relationship we want to investigate. In section 5, we formulate our research questions and we present results obtained through a survey study.

\section{DAFC: A Knowledge and Learning Perspective}

In conventional agrifood supply chain, knowledge processes need long learning time before they can be mastered. In such chains, knowledge and information become rapidly outdated. The long physical distance from decisions to their effects and feedback heavily affect decision-making processes.

In a DAFC, the particular partnership among producers enables new learning by continuously identifying routines that need to be modified or renewed. Furthermore, direct interactions between producers and consumers allow producers to learn faster and better, thanks to rapid and not mediated feedback cycles, thus becoming an essential element of competitive advantage.

Interaction-based learning processes, carried out in an informal way, empower actors and allow them to create a non-competitive learning context that produces 
higher-degree knowledge processes. They allow the explicating of tacit knowledge through experience sharing (learning by doing and peer-to-peer exchange).

The learning relationships between producers and consumers in a DAFC are enabled by the exchange of local lay knowledge more than the expert or managerial ones. It can revitalize local/traditional knowledge [4] and encourage sustainable land management [5]. Moreover, it engenders trust and cooperation within a community [1], and it is also an important way to educate consumers about where their food comes from, including the environmental and social conditions of its production.

Learning interactions have two main dimensions: the process and the contextual one. The first one is represented by social practices in a learning event. The second one regards the learning event which provides the social framework within which learning can occur. The basic idea is that learning occurs in a well-defined sociocultural context characterized by features like the societal and institutional values which prevail at any one time.

Learning happens in different ways. On one side, consumers may learn the story and background of the producer, and the cultural significance behind a product tied to specific method or place of production. Moreover, they may "recover skills and knowledge that have been lost along with the change of purchasing and eating habits. For example, knowing seasonality and variety of vegetables (there are a lot of species unknown to citizens), learning how to cook them (to make them edible and more tasty, but also less monotonous), and how to preserve them "[6]. On the other side, the interactions with consumers lead producers to face new systems of activities and new technical, managerial and marketing choices. In many DAFCs, consumers negotiate collectively with the farmer(s) the production/distribution process. In such negotiations farmers may learn about consumers' taste and culinary uses, and consumers about farmers' production/distribution constraints. Thanks to personal interactions with their regular customers, producers can learn about customer receptivity to products and services and generate ideas about new products/services.

\section{Basic Forms of DAFCs}

DAFCs have been developed in many countries shaping different organizational forms in many grassroots initiatives promoted both by producers and consumers. In what follows, we summarize main forms of DAFCs reported in literature. They are to be considered as "basic" forms that could be combined to shape different DAFCs.

Direct (on farm) sale - DoFS: it is based on producer-consumer face to face transactions in the place/space of production. DoFS includes on-farm stores (FS), or roadside stands, where a grower establishes a selling stand for agrifood products grown on his own farm; agritourisms (AT) which promote and direct sale the farm products allowing visitors to take part in agricultural activities for recreation or leisure purposes, or complementary activities like hospitality, meal provision, agricultural festivals, farm tours and educational activities [7]; pick your own operations (PYO), allowing consumers to gather products by their own directly from the field [8]. 
Box schemes - BSs: they involve local consumption groups and famers' cooperatives participating to a common agreement to ensure a regular procurement of seasonal food grown up in a sustainable way in the local community or its close surroundings [2]. Consumers agree to buy available seasonal food (fruit, vegetables, meat or cheese) from producers who are responsible to delivery periodically at the consumers' home [2]. In Community-supported agriculture (CSA), community members purchase a share of agricultural production by paying in advance, assuming the risk/benefit of a poor or very productive season with the manufacturer.

Farmers' markets - FMs: These are markets, generally placed in urban areas and with periodic frequency, where a group of farmers meets and where each producer direct sell his own agri-food product to single customers attending the market. Two main features characterize a FM: first, sold products are "local" (usually produced within $50 \mathrm{~km}$ from the market place); second, manufacturers are directly involved in sales. In some occurrence FMs evolve into collective farmer shops (CFSs), where farmers act together to set up and jointly manage a shop in a market town where products are sold (usually every day) by some of the farmers themselves [2].

Collective buying groups - CBGs: organized consumers that choose to commonly buy directly from selected producers. Group members are nodes of a network aimed to acquire and share information, as well as to define quality criteria for products to purchase. The interaction among producers and group members is mediated by a group leader. Consumers decide to share their "shopping lists" to create a unique cumulative order submitted, by the leader, to each producer who is charged to deliver ordered products to a unique pick up site [6].

Collective kitchens or Community kitchens - CKs: they are community based cooking programs where small groups of people come together at designated times (e.g., weekly, monthly) to buy in bulk and cook healthy local food that often is eaten together or is taken home to their families. CKs allow participants to share resources (kitchens, and cooking facilities), the costs of food and food preparation labor, as well as provide means for socializing with other community members [9]. In some cases, local farmers team up with CKs' participants, providing advices and support.

\section{Face to Face Interactions and Learning Opportunities}

Although the above described DAFC forms are mainly focalized on distribution/selling processes, each of them provide a sort of liminal space that subverts the normal experience of food shopping and where a variety of local lay knowledge related to agriculture, rural economy, the environment, food production, healthy eating and consumer values, may be exchanged [4].

Beyond the immediacy of the transaction between producers and consumers, the social context of any DAFCs provides an arena for social learning and knowledge exchange. As matter of fact, many multifaceted DAFC initiatives involve economic relations which transcend the boundaries of profitability and are built on F2FIs.

Here, a F2FI is regarded as the process in which two or more persons are physically co-present (in a way that allows for mutual visual and physical contact) 
and influence each other's actions. Face to face communication is a fundamental part of any F2FI, since it allows people to be sending and delivering messages almost simultaneously, in a cycle of interruption, feedback and possible repair the F2FI.

F2FIs enable learning processes and let both producers and consumers benefit from the shorter distances, better information flow and greater trust between them [1]. Much of the potential of development of DAFC initiatives lies in building new relations through which a large share of 'tacit knowledge' can be made explicit and shared through the activation of a learning and societal embedding process.

Any notion of social learning presupposes interactions between the social actors themselves and the social, economic, physical and environmental context where they employ (this aspect refers to the 'embeddedness' of learning, [10]). Two main assumptions underpin our LO identification framework for DAFCs:

- F2FIs have the potential to result in a learning and/or knowledge exchange process. We conceive these interactions as opportunities for communicative/instrumental learning [11], and exchange of experiences.

- Any LO is associated with attribute values of a F2FI and the context embedding it.

Under these assumptions, a LO for actors in a DAFC is provided by a F2FI in which many sensory, cognitive and social cues could allow to connect the communication content with the social, economic, physical and environmental context that embeds it. These cues are context-dependent, since they are related to things from the environment and situation where learning may occur. They may regard the F2FI location, the appearance, taste, and consistency of an agri-food product, and so on.

In this sense, a LO can be regarded as an affordance for "understanding more about the perspectives and interests of others, what others mean, and how to communicate one's own meaning, to make sense of and relate to the particular context within which the communication takes place" [11]. In our framework, we consider F2FI attributes that play a significant role in providing opportunities for learning from context during a F2FI that takes place in a DAFC:

Communication Content Orientation (CO): it specifies the category of topic is talked about. Categories are oriented to products ( e.g. seasonality, varieties, taste shapes, textures and aromas), actors (e.g., trustworthiness of other peers, consumers' wishes), primary and secondary activities (e.g., agricultural practices, processing methods, food preparation), organization culture (e.g. norms, values, history, experiences), social, economic and natural environment (e.g. terroir, traditions, customs, laws);

Interaction Participants Role (IPR): it is the DAFC role of participants to a contextualized F2FI. Factor values are "consumers with consumers", "producers with producers" and "consumers with producers";

Interaction Timing (IT): it is the DAFC activity stage ("production", "distribution", "consumption", and "waste management") at which the contextualized F2FI occurs;

Interaction Place (IP): it specifies the location of the place where the contextualized F2FI occurs. Such locations are typed as "farm site", where DAFC product is coming from, "agri-food terroir", i.e. the land bestowed upon DAFC 
product, "proximate area", i.e. an area (e.g. urban area) that is proximate to the agrifood terroir;

Participant Motivation (PM): it specifies the type of motivation for the participation to DAFC activities. Participation is seen in terms of expressing and discussing ideas, developing plans, evaluating actions, and decision-making. Motivation types are social (e.g. tighter relationship with others, social belonging.), ecological (e.g. lower environmental impact), economical (e.g. disposable income/budget impact), and personal wellbeing (e.g. physical and mental health, pleasant time).

The values of these attributes depend on the particular form of the DAFC, and they have a great importance in creating good opportunities for learning about the F2FI context. The learning opportunity domain is hierarchically structured as follows:

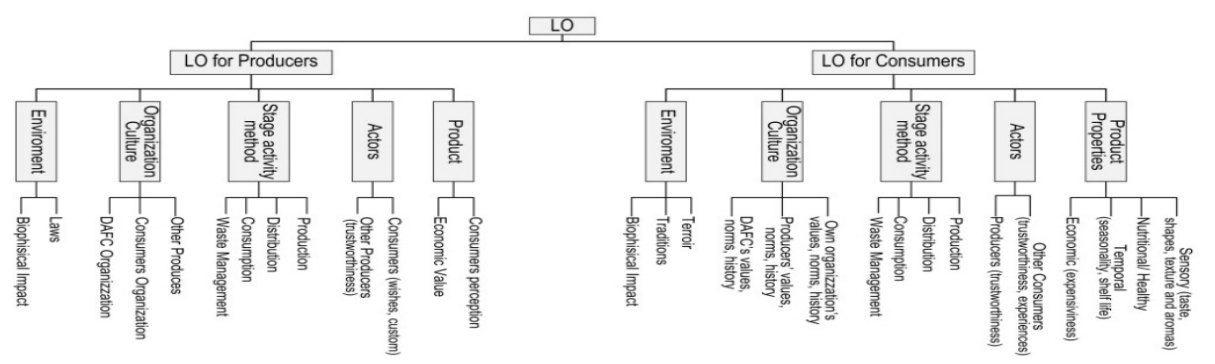

\section{The Survey Research}

Our aim is to find out: which are the main LOs arising from initiatives of DAFCs that exhibit the same basic form; which F2FI attributes values should be considered important for LOs detected in DAFCs initiatives with the same organization form.

In our study, we surveyed 330 initiatives by gathering data from three sources of information: documentation (scientific papers and project reports describing case studies of DAFC), web sites (examination of the description of F2FIs in DAFC experiences) and direct observation (unstructured interviews to farmers, store managers, consumers, and consumers groups leader, involved in Italian DAFC cases).

We have employed a methodology that is based on three main steps: (I) collect a relevant set of real world DAFC case studies and group them according to their organizational form type. In our study we have considered the basic forms listed in in section 3; (II) for each group, identify F2FI attributes values that are considered to be relevant for some LOs; (III) detect the most frequent LOs in the (reported or directly observed) case studies of each group, and map them onto the LO domain described in section 4 . The obtained results are summarized in table 1, table 2 and table 3. (where $c r=$ consumer, $p r=$ producer, $p n=$ production, $d n=$ distribution, $c n=$ consumption, $o n=$ organization, $w m=$ waste management, $e n v=$ environment). 
Table 1. F2FI attribute values in DAFC basic forms

\begin{tabular}{|l|l|l|l|l|l|}
\hline & \multicolumn{1}{|c|}{ DoFS } & \multicolumn{1}{c|}{ BS } & \multicolumn{1}{c|}{ FM } & \multicolumn{1}{c|}{ CBG } & \multicolumn{1}{c|}{ CK } \\
\hline CO & $\begin{array}{l}\text { Products; activities; } p r \\
\text { history and values; } e n v .\end{array}$ & $\begin{array}{l}\text { Products; activities; } \\
p r \text { history and values; } \\
c r \text { wishes; } e n v .\end{array}$ & $\begin{array}{l}\text { Products; } \\
\text { activities; } p r \\
\text { history; } c r \text { wishes. }\end{array}$ & $\begin{array}{l}\text { Products; activities; } \\
c r \text { wishes } p r \text { history } \\
\text { and values; } e n v .\end{array}$ & $\begin{array}{l}\text { Products; } \\
\text { activities. }\end{array}$ \\
\hline IPR & $c r / p r$ & $c r / p r ; c r / c r ; p r / p r$ & $c r / p r ; p r / p r ; ~(2)$ & $c r / c r ; c r / p r ;(3)$ & $c r / c r ;$ \\
\hline IT & $p n$ (PYO); $d n$ (FS); $c n($ AT) & $p n(\mathrm{CSA}) ; d n$ & $d n$ & $d n$ & $c n$ \\
\hline IP & farm site; & proximate area & $\begin{array}{l}\text { proximate area; } \\
\text { agri-food terroir }\end{array}$ & proximate area & $\begin{array}{l}\text { proximate } \\
\text { area }\end{array}$ \\
\hline PM & $\begin{array}{l}\text { Economical; personal } \\
\text { wellbeing; (1) }\end{array}$ & $\begin{array}{l}\text { Ecological; Social; } \\
\text { personal wellbeing; }\end{array}$ & $\begin{array}{l}\text { Economical; } \\
\text { Social; }\end{array}$ & $\begin{array}{l}\text { Economical; } \\
\text { Social; Ecological }\end{array}$ & $\begin{array}{l}\text { Economical } \\
\text { Social }\end{array}$ \\
\hline
\end{tabular}

\section{Notes for Table 1:}

(1): PYO is addressed to consumers who look for fresh and quality products at a reduced price by letting them to make direct connections with the place/space of production. In addition, consumers may enjoy the gathering as a recreational experience [8].

(2): FMs afford intensive, periodic opportunities for vendors to interact directly both with their customers and with other farmers' market vendors [12].

(3): Consumers have periodic meetings planned by the CBG; producers regularly meet with CBG leaders [6].

Table 2. LOs for Consumers in DAFC basic forms

\begin{tabular}{|c|c|c|c|c|c|}
\hline & DoFS & BS & FM & CBG & CK \\
\hline $\begin{array}{l}\text { Product } \\
\text { properties }\end{array}$ & $\begin{array}{l}\text { Sensory; } \\
\text { Temporal }\end{array}$ & $\begin{array}{l}\text { Sensory; Temporal; } \\
\text { Economic; Healthy; }\end{array}$ & $\begin{array}{l}\text { Sensory; } \\
\text { Temporal } \\
\text { Economic; }\end{array}$ & $\begin{array}{l}\text { Sensory; Temporal; } \\
\text { Economic; Healthy }\end{array}$ & $\begin{array}{l}\text { Sensory; } \\
\text { Nutritional/ } \\
\text { healthy;(5) }\end{array}$ \\
\hline Actors & $p r$ & pr.; other crs. & $p r$ & other crs; & other $c r s$ \\
\hline activity method & $p n ; d n$ & $p n ; d n ; c n ; w m ;(\mathbf{3})$ & $p n ; c n ;(4)$ & $d n ; c n$ & $c n ; w m ;$. \\
\hline Org. Culture & $\begin{array}{l}p r \text { values, } \\
\text { norms, } \\
\text { history; (1) }\end{array}$ & $\begin{array}{l}\text { own on; DAFC } \\
\text { values, norms, } \\
\text { history; } p r \text { values, } \\
\text { norms, history; }\end{array}$ & $\begin{array}{l}\text { DAFC values, } \\
\text { norms, history } \\
p r, \text { history; }\end{array}$ & $\begin{array}{l}\text { own on; DAFC values, } \\
\text { norms, history } p r \\
\text { values, norms, history; }\end{array}$ & own or. \\
\hline Enviroment & $\begin{array}{l}\text { Terroir; } \\
\text { Tradition;(2) }\end{array}$ & $\begin{array}{l}\text { Terroir; Tradition; } \\
\text { Biophisical Impact; }\end{array}$ & Tradition; & Biophisical Impact; & Tradition \\
\hline
\end{tabular}

\section{Notes for Table 2:}

(1): DoFSs offer opportunities to better understand, the culture and values of the people involved in farming and the production methods employed [8].

(2): While consumers are travelling to the rural countryside to purchase agrifood, they may learn the original cultural, geographical and economic context linked to the food [2].

(3): In BS, consumers negotiate collectively with the farmer(s) over the process of production and distribution (e.g., the content of the box over the growing season, the choice of crop varieties, etc.). As the content of the box is imposed by food seasonality, they recover skills and knowledge on local variety of vegetables as well as they learn how to cook within the offerings of the season. In some cases, BSs and CSA subscribers are engaged in waste management and compost production.

(4): Consumers may learn about vendors and their food production practices as well as how to use the products in cooking (recipes, storage, varieties) [11].

(5): CKs offer to participants LOs about the importance of healthy eating with an increased variety of local foods in their diets through the social interaction among participants [9] 
Table 3. LOs for Producers in DAFC basic forms

\begin{tabular}{|c|c|c|c|c|c|}
\hline & DoFS & BS & FM & CBG & CK \\
\hline Product & $\begin{array}{l}c r \\
\text { perception }\end{array}$ & cr perception; & $\begin{array}{l}\text { cr } \text { perception; } \\
\text { Economic Value; }\end{array}$ & cr perception & $\begin{array}{l}r \\
\text { perception }\end{array}$ \\
\hline Actors & $\mathrm{cr}$ & cr; other prs & cr; other prs; (1) & $\mathrm{cr}$ & \\
\hline \begin{tabular}{l|} 
Activity \\
Changes needs
\end{tabular} & $d n$ & $p n ; d n$ & $p n ; d n ;(2)$ & $d n$ & \\
\hline Org. Culture & & cr's on; DAFC' on & other $p r ;$ DAFC on;(3) & cr's on & cr's on \\
\hline Enviroment & & Biophisical Impact & Laws & Laws; Biophisical impact & \\
\hline
\end{tabular}

\section{Notes for Table 3:} [12].

(1): Producers may learn about consumers' demand and products offered by other vendors

(2): Producers may learn about new products to be developed and new ways of marketing them. Such LOs are supported by the generation and circulation of knowledge enabled through the feedback coming from the producers-consumers interaction and from the interaction with other vendors. In CFSs, farmers have LOs about management logics typical of a distribution structure that encompasses and exceeds that of the individual producer [12].

(3): Producers adhering to FMs and CFSs share agreement to regulate the behavior of individual producers, the market/store management and the joining of new participants [12].

\section{Conclusions}

The rationale of our research was to identify the main F2FI attributes values, that can represent important factors for LOs, in each DAFC basic form. In our opinion, the obtained results can be utilized in conceiving social network services that expand LOs well beyond traditional DAFC settings. To see that, imagine a DAFC wireless community where all members are provided with access to mobile handheld devices and advanced social networking services to enhance LOs inside and outside the "space" where F2FIs take place. Such enhancement may happen through providing more accurate information to the right people, at the right time, and at the right place (e.g. giving people support to meet their social, economic and cultural needs, increasing trust in products, processes, people and experiences). Since F2FIs and LOs depend on the particular nature of a DAFC, we have highlighted important issues for effective social networking services aimed to expand LOs in each DAFC basic form.

Acknowledgments. This work has been conducted as part of the AGROMATER project.

\section{References}

1. Watts, D., Ilbery, B., Maye, D.: Making reconnections in agro-food geography: alternative systems of food provision. Progress in Human Geography 29(1), 22-40 (2005)

2. Sánchez Hernández, J.L.: Alternative Food Networks: concept, typology and adaptation to the spanish context. Boletín de la A.G.E. (49), 375-380 (2009)

3. Volpentesta, A.P., Ammirato, S.: Alternative agrifood networks in a regional area: a case study. To appear in International Journal of Computer Integrated Manufacturing 
4. Fonte, M.: Knowledge, Food and Place. A Way of Producing, a Way of Knowing. Sociologia Ruralis 48(3), 200-222 (2008)

5. Ilberry, B., Maye, D.: Alternative (shorter) food supply chains and specialist livestock products in the Scottish-English borders. Enviroment and Planning A 37, 823-844 (2005)

6. Rossi, A., Brunori, G.: Drivers of transformation in the agro-food system. GAS as coproduction of Alternative Food Networks. In: Darnhofer, I., Grötzer, M. (ed.) Proceedings of 9th European IFSA Symposium, Vienna Au., pp. 1913-1931 (2010)

7. Tew, C., Barbieri, C.: The perceived benefits of agritourism: The provider's perspective. Tourism Management, 215-224 (2012)

8. Lloyd, R.M., Tilley, D.S., Nelson, J.R.: Pick-Your-Own Markets. In: Direct Farm Marketing and Tourism 62. In: Tronstad, R., Leones, J. (eds.) Tuscon, Arizona (1995)

9. Drake, J.: Community-Based Alternative Food Source Models; Livable New York Sustainable Communities for all ages; Cap IV.1.k, http: / / www .aging.ny.gov

10. Granovetter, M.: Economic Action and Social Structure: The Problem of Embeddedness. American Journal of Sociology 91(3), 481-510 (1985)

11. Milestad, R., Westberg, L., Geber, U., Bjorklund, J.: Enhancing Adaptive Capacity in Food Systems - Learning at Farmers' Markets in Sweden. Ecology \& society 15(3), 29 (2010)

12. Hinrichs, C.C., Gillespie, G., Feenstra, G.: Social Learning and Innovation at Retail Farmers' Markets. Sociologia Ruralis, 31-58 (2004) 